\title{
ADIÇÃO DE INULINA EM BOLO DE CHÁ VERDE: análise físico-química e aceitabilidade sensorial entre crianças
}

\author{
Michele DAL SANTOS ${ }^{1}$ \\ Jamile Kailer dos SANTOS ${ }^{2}$ \\ Ana Paula Justino RIBAS ${ }^{3}$ \\ Nathália MEOTTI ${ }^{4}$ \\ Elisvânia Freitas dos SANTOS ${ }^{5}$ \\ Daiana NOVELLO 6
}

${ }^{1}$ Nutricionista, Universidade Estadual do Centro-Oeste (UNICENTRO). micheledalsantos@outlook.com

${ }^{2}$ Nutricionista, Universidade Estadual do Centro-Oeste (UNICENTRO). jamile@gmail.com

${ }^{3}$ Nutricionista, Universidade Estadual do Centro-Oeste (UNICENTRO). anaribas@ hotmail.com

${ }^{4}$ Nutricionista, Universidade Estadual do Centro-Oeste (UNICENTRO). natimeot@ hotmail.com

${ }^{5}$ Professora, Doutora, Departamento de Nutrição, Universidade Federal de Mato Grosso do Sul (UFMS). elissantos@gmail.com

${ }^{6}$ Professora, Doutora, Departamento de Nutrição (UNICENTRO). nutridai@gmail.com.

Recebido em: 25/10/2015 - Aprovado em: 16/07/2016 - Disponibilizado em: 18/12/2016

RESUMO: Objetivou-se verificar a aceitabilidade sensorial de bolo de chá verde adicionado de inulina e determinar a composição físico-química da formulação tradicional e daquela contendo inulina com aceitação sensorial semelhante a padrão. Foram desenvolvidas as seguintes formulações de bolo de chá verde: F1 (padrão) e as demais adicionadas de 3\% (F2), 6\% (F3), 9\% (F4) e 12\% (F5) de inulina. Participaram da avaliação sensorial 55 provadores não treinados, de ambos os gêneros, com idade entre 9 e 10 anos. Nas análises físico-químicas foram determinados o teor de umidade, cinzas, proteínas, lipídios, carboidratos, fibra bruta e valor calórico. Os resultados da análise sensorial mostraram que a adição de 9\% de inulina foi a amostra com o maior teor e com aceitação semelhante a padrão nos atributos aparência, aroma, sabor, textura, cor, bem como aceitação global e intenção de compra. A análise físico-química mostrou maiores teores de umidade e calorias na formulação F1 comparada com F4, sendo que esta mostrou maiores teores de fibra bruta $(\mathrm{p}<0,05)$. Não houve diferença estatística entre os teores de cinzas, lipídios, carboidratos e proteínas entre as duas formulações. Assim, a elaboração dos produtos permitiu comprovar que, um nível de adição de até $9 \%$ de inulina em bolo de chá verde foi bem aceito pelos provadores, obtendo-se aceitação sensorial semelhante ao produto padrão e com boas expectativas de comercialização.

Palavras-chave: Panificação. Alimentos funcionais. Fibra alimentar.

\section{ADDITION OF INULIN IN GREEN TEA CAKE: physico-chemical analysis and sensory acceptability among children}

ABSTRACT: This study aimed to verify the sensory acceptability of green tea cake added inulin and determine the physico-chemical composition and that the traditional formulation containing inulin with sensory acceptance similar to standard. The following formulations were developed cake green tea: F1 (standard) added and the remaining 3\% (F2), 6\% (F3), 9\% (F4) and 12\% (F5) inulin. Participated in the sensory evaluation 55 untrained tasters, of both genders, aged between 9 and 10 years. In the physico-chemical analyzes were determined moisture content, ash, protein, fat, 
carbohydrates, crude fiber and calories. The results of sensory analysis showed that the addition of $9 \%$ inulin was the sample with the highest level and with similar acceptance in the standard attributes appearance, aroma, flavor, texture, color and overall acceptance and purchase intent. The physico-chemical analysis showed higher moisture content and calories in F1 compared with F4 formulation, and this showed higher levels of crude fiber ( $\mathrm{p}<0.05$ ). There was no statistical difference between the levels of ash, lipids, carbohydrate and proteins between the two formulations. Thus, the development of products has demonstrated that an addition level up to $9 \%$ of inulin of green tea cake was well accepted by the panelists to give sensory acceptance similar to standard product and good expectations of sales.

Keywords: Bakery. Functional foods. Dietary fiber.

\section{INTRODUÇÃO}

Atualmente, devido ao maior interesse da população na promoção e manutenção da saúde, tem se optado por uma alimentação saudável associada à prática de atividade física. Além disso, vem aumentando o consumo de produtos naturais aos quais têm sido atribuídas propriedades medicinais (MUCCILLOBAISCH et al., 2009).

A espécie Camellia sinensis, popularmente conhecida como chá-verde, tem origem asiática e é hoje considerado um alimento funcional que apresenta em sua composição flavonóides (antioxidantes), metilxantinas, antiinflamatórios estimulantes e anticarcinogênicos. Tem efeito na redução do risco de doenças crônicas como a hipercolesterolemia, diabetes mellitus, hipertensão arterial, obesidade, além de outros benefícios medicinais quando consumidos diariamente (ZHANG et al., 2006; MUCCILLO-BAISCH et al., 2009; BENEO ${ }^{\circledR}$
Outro alimento em destaque por suas características funcionais é a inulina, que é classificada como uma fibra solúvel e fermentável, não digerível pelas enzimas do trato gastrointestinal. Atua no intestino estimulando o crescimento e a atividade de bactérias do cólon (SAAD, 2006; SANTOS et al., 2006). Consequentemente melhora a resistência à colonização e previne a translocação bacteriana, contribuindo assim, nas funções químicas e enzimáticas de proteção ao trato gastrintestinal (ROBERFROID, 2005).

Sabe-se que os hábitos alimentares adequados iniciam-se na infância, e, dessa forma, o ambiente escolar é favorável e privilegiado para o estímulo no consumo de alimentos saudáveis (BRASIL, 2003). Assim, torna-se relevante a introdução de uma alimentação balanceada, composta também por alimentos funcionais, na faixa etária escolar (7 aos 10 anos), pois uma vez adquiridos os hábitos corretos, dificilmente serão modificados na idade adulta (ZHANG et al., 2006).

HP, 2015). 
Portanto, uma estratégia útil para o aumento do consumo de alimentos funcionais por esta faixa etária seria adicionar inulina em produtos de panificação, como os bolos que são alimentos muito consumidos por crianças, melhorando dessa forma a qualidade sensorial e nutricional do produto (MOSCATTO et al., 2004; APLEVLICZ; DIAS, 2010). Porém, o sucesso de novos produtos no mercado depende de seu desempenho junto ao consumidor. Desta forma, os testes sensoriais são ferramentas de extrema importância para o desenvolvimento, aceitação e preferência desses alimentos (MINIM, 2010), também para o público infantil (GASTALDON et al., 2007).

Os testes de aceitabilidade buscam determinar a aceitação e a preferência do alimento para assim verificar a qualidade do mesmo, principalmente entre crianças. Este tipo de teste têm se tornado cada vez mais importante para a indústria de processamento de alimentos, devido ao aumento do número de produtos direcionados ao mercado infantil e ao seu poder em decisões de compra. Além disso, este método tem sido utilizado para verificar a aceitação da merenda escolar pelo Programa Nacional de Alimentação Escolar (PNAE) (CECANE, 2010).

O objetivo deste estudo foi desenvolver formulações de bolos adicionados de chá verde e inulina e verificar sua aceitabilidade sensorial, entre crianças, bem como avaliar a composição físico-química do produto padrão e daquele com maior teor de inulina e aceitação semelhante ao padrão.

\section{MATERIAL E MÉTODOS}

\section{Aquisição da matéria-prima}

Os produtos foram adquiridos em supermercados do município de Guarapuava, PR e a inulina foi doada por empresas nacionais parceiras.

\section{Formulação dos produtos}

Foram elaboradas cinco formulações de bolo de chá verde, sendo: F1 padrão (0\%), e as demais adicionadas de 3\% (F2), 6\% (F3), 9\% (F4) e $12 \%$ (F5) de inulina. Estes níveis de adição foram definidos através de testes sensoriais preliminares realizados com o produto. Além das porcentagens de inulina, os ingredientes utilizados nas formulações foram: farinha de trigo (28,76\%), ovos (24,54\%), iogurte natural $(15,82 \%)$, óleo de soja (13,61\%), açúcar cristal (F1: 12\%, F2: 9\%, F3: 6\%, F4: 3\% e F5: 0\%), gelatina sabor limão $(2,88 \%)$, chá verde $(1,53 \%)$ e fermento químico $(1,34 \%)$.

As formulações foram preparadas, individualmente, no Laboratório de Técnica 
Dietética do Departamento de Nutrição da UNICENTRO.

Inicialmente foram misturados os ingredientes secos (farinha de trigo, açúcar, gelatina e fermento) em uma vasilha e reservouse. Em seguida, foram batidos em liquidificador $\left(\right.$ Mondial $^{\circledR}$, Brasil) os demais ingredientes: ovos, óleo, iogurte, inulina e o chá verde aproximadamente 5 minutos, até se obter uma consistência homogênea. Esta mistura foi adicionada aos ingredientes secos anteriormente misturados, sendo homogeneizada manualmente por 5 minutos.

Após este processo, as formulações foram dispostas em formas de alumínio (33 x $22 \mathrm{~cm}$ ) untadas com óleo e assadas em forno convencional $\left(\right.$ Consul $^{\circledR}$, Brasil) pré-aquecido a $180{ }^{\circ} \mathrm{C}$, por 30 minutos.

\section{Análise sensorial}

Participaram da pesquisa 55 provadores não treinados sendo crianças devidamente matriculadas em uma Escola Municipal de Guarapuava, PR, de ambos os gêneros, com idade entre 9 e 10 anos.

Os produtos foram submetidos à análise sensorial, em uma sala da escola. Cada prova foi feita em cabines individuais, tipo urna, sendo que o provador foi auxiliado pelas pesquisadoras para o preenchimento das respostas.

Foram avaliados os atributos de aparência, aroma, sabor e textura. Os provadores avaliaram a aceitação das amostras através de uma escala hedônica facial estruturada de 7 pontos variando de 1 ("super ruim”) a 7 (“super bom”), adaptada de Kimmel et al. (1994). Foram aplicadas também, questões de aceitação global e intenção de compra analisados através de uma escala estruturada de 5 pontos (1 "desgostei muito"/ "não compraria" a 5 "gostei muito"/ "compraria com certeza"), como sugerido por Minim (2010).

Os julgadores receberam uma porção de cada amostra (aproximadamente $10 \mathrm{~g}$ ), em pratos plásticos descartáveis brancos, codificados com números de três dígitos, de forma casualizada e balanceada, acompanhados de um copo de água. As formulações foram oferecidas aos julgadores de forma monádica sequencial.

\section{Índice de aceitabilidade (IA)}

O cálculo do IA das formulações foi realizado segundo a fórmula: $I A(\%)=A x$ 100/B (onde: $A=$ nota média obtida para o produto e $B=$ nota máxima dada ao produto) (MONTEIRO, 1984). 


\section{Composição físico-química}

As análises físico-químicas foram realizadas no Laboratório de Físico-Química da Unidade de Tecnologia de Alimentos e Saúde Pública (UTASP) da UFMS.

As seguintes determinações foram realizadas, em triplicata, na formulação padrão e naquela com maior teor de inulina e com aceitação sensorial semelhante a padrão: Umidade: Foi determinada em estufa a $105{ }^{\circ} \mathrm{C}$ até o peso constante, segundo Official Methods of Analysis of AOAC International (AOAC, 2011). Cinzas: Foram analisadas em mufla (550 $\left.{ }^{\circ} \mathrm{C}\right)$, conforme AOAC (2011). Lipídios totais: Utilizou-se o método de extração a frio, segundo Bligh e Dyer (1959). Proteínas: Foram avaliadas através do teor de nitrogênio total da amostra, pelo método Kjeldahl, determinado ao nível semimicro (AOAC, 2011). Utilizou-se o fator de conversão de nitrogênio para proteína de 6,25. Fibra alimentar: Avaliada por cálculo teórico (TACO, 2011; BENEO $^{\circledR} \mathrm{HP}, 2015$ ). Carboidratos: A determinação de carboidratos (incluindo fibra) dos produtos foi realizada através de cálculo teórico (por diferença) nos resultados das triplicatas, conforme a fórmula: $\%$ Carboidratos $=100-(\%$ umidade $+\%$ proteína $+\%$ lipídios $+\%$ cinzas $) ;$ Valor calórico total: O total de calorias (kcal) foi calculado utilizando-se os valores de Atwater (ou calor de combustão) para lipídios (9 kcal/ g), proteína (4 kcal/ g) e carboidratos $(4 \mathrm{kcal} / \mathrm{g})$ (ATWATER; WOODS, 1896) e o valor de 1,5 kcal/ g para os carboidratos vindos da inulina (BENEO $^{\circledR}$ HP, 2015).

\section{Determinação do Valor Diário de Referência (VD) \\ O VD foi calculado em relação a $50 \mathrm{~g}$} da amostra, com base nos valores preconizados para crianças (9 a 10 anos) (DRI, 2005). Os nutrientes foram avaliados pelo cálculo médio dos provadores, resultando em: 2076,2 kcal/ dia, 282,1 g/ dia de carboidratos, 71,3 g/ dia de proteínas, 75,6 g/ dia de lipídios e 13,86g/ dia de fibra alimentar.

\section{Análise Estatística}

Os dados foram analisados com auxílio do software Statgraphics Plus ${ }^{\circledR}$, versão 5.1, através da análise de variância (ANOVA). A comparação de médias foi realizada pelo teste de médias de Tukey e t de student, avaliados com nível de 5\% de significância.

\section{Questões éticas}

Este trabalho foi aprovado pelo Comitê de Ética em Pesquisa da UNICENTRO, parecer número $\mathrm{n}^{\mathrm{o}}$ 49549/2012. Entretanto, como critérios de exclusão foram considerados os seguintes fatores: possuir alergia a algum 
ingrediente utilizado na elaboração dos bolos, não ser aluno da escola em questão e não entregar o Termo de Consentimento Livre e Esclarecido (TCLE) assinado pelo responsável legal.

\section{RESULTADOS}

\section{Análise sensorial}

Por meio da Tabela 1 pode-se verificar o resultado da avaliação sensorial dos bolos de chá verde padrão e adicionados de inulina.

Tabela 1. Médias do teste sensorial afetivo e intenção de compra realizados para os bolos de chá verde adicionados de inulina

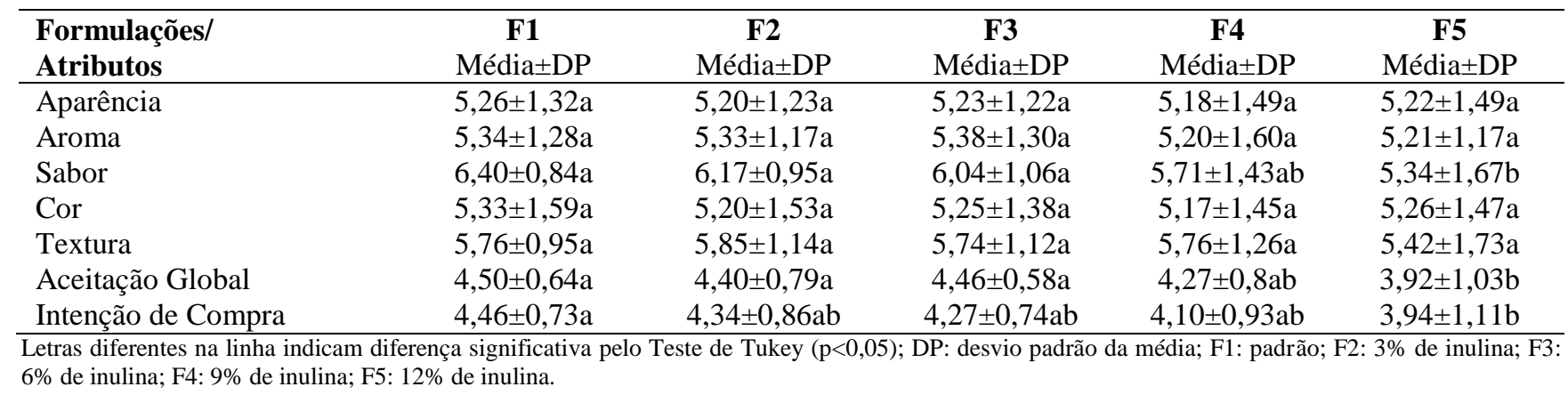

Não houve diferença estatística $(\mathrm{p}>0,05)$ entre as formulações nos atributos aparência, aroma, cor e textura. Em relação ao sabor, aceitação global e intenção de compra dos produtos, a formulação padrão (F1) apresentou maior aceitação $(\mathrm{p}<0,05)$ que $\mathrm{F} 4$, sem diferença estatística das demais.

A Figura 1 apresenta a distribuição dos provadores pelos valores hedônicos para cada atributo sensorial.

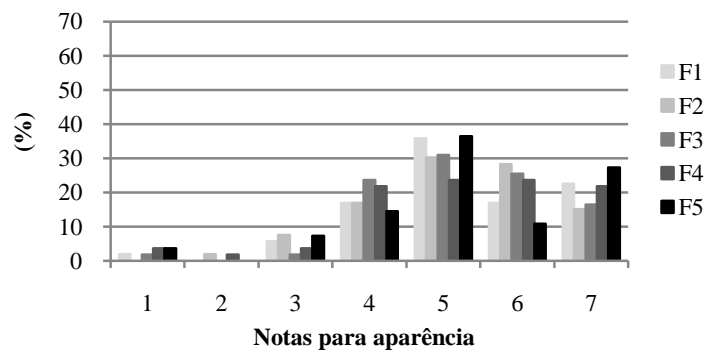



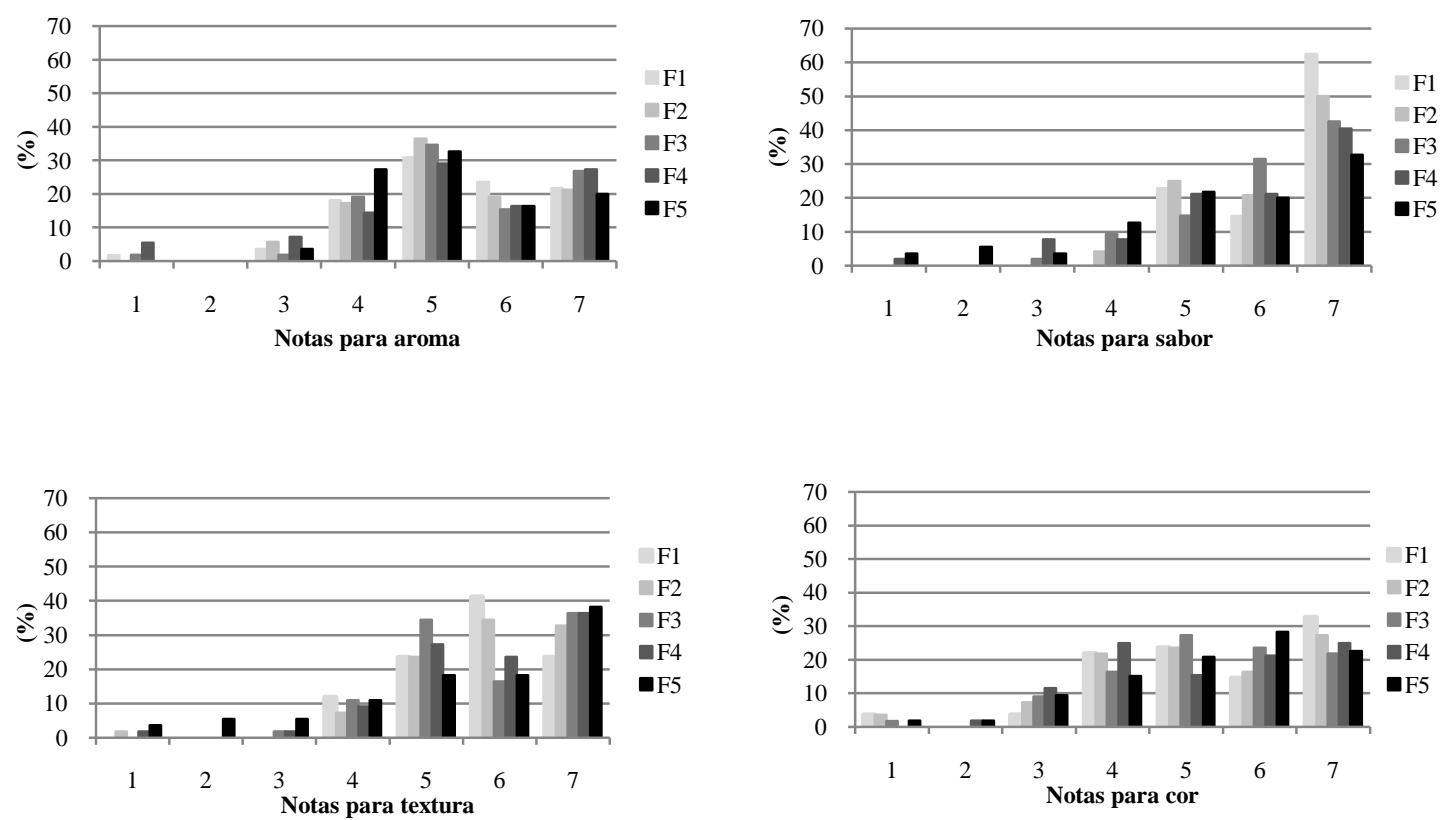

Figura 1. Distribuição dos provadores pelos valores hedônicos obtidos na avaliação dos atributos aparência, aroma, sabor, textura e cor das formulações de bolo de chá verde adicionadas de 0\% (F1), 3\% (F2), 6\% (F3), 9\% (F4) e 12\% (F5) de inulina.

Em geral, houve uma concentração maior das notas acima de 5 ("bom"), em todos os atributos. Destaca-se a elevada porcentagem de provadores que marcaram a nota 7 ("super bom"), no atributo sabor, em todas as inulina nos bolos foi bem aceita pelo público infantil.

Por meio da Figura 2 pode-se verificar o índice de aceitabilidade das formulações avaliadas, em relação aos atributos sensoriais. formulações, demonstrando que a adição de

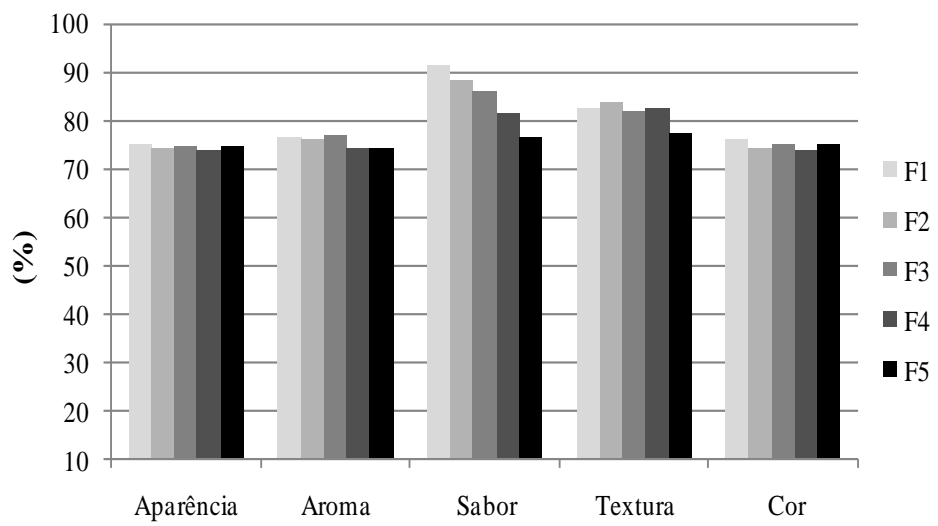

Figura 2. Índice de aceitabilidade do bolo de chá verde adicionados de 0\% (F1), 3\% (F2), 6\% (F3), 9\% (F4) e 12\% (F5) de inulina, em relação aos atributos avaliados. 
Todas as amostras apresentaram IA acima de $70 \%$, com destaque para os atributos sabor e textura que tiveram as avaliações mais elevadas.

\section{Composição físico-química}

Na Tabela 2 está descrita a composição físico-química e valores diários recomendados (VD) do bolo de chá verde padrão e acrescido de $9 \%$ de inulina, comparados com um produto referência.

Tabela 2. Composição físico-química de bolo padrão (F1) e adicionados de $9 \%$ de inulina (F4), comparadas com \% de valores diários recomendados - VD* (porção média de $50 \mathrm{~g}$ ), comparadas com um produto referência**

\begin{tabular}{|c|c|c|c|c|c|}
\hline \multirow[b]{2}{*}{ Avaliação } & \multicolumn{2}{|l|}{ F1 } & \multicolumn{2}{|c|}{$\mathbf{F 4}$} & \multirow[b]{2}{*}{ Referência** } \\
\hline & Média $\pm \mathrm{DP}$ & $\% \mathrm{VD}^{*}$ & Média $\pm \mathrm{DP}$ & $\% \mathrm{VD}^{*}$ & \\
\hline Umidade (\%) & $29,73 \pm 0,01 \mathrm{a}$ & ND & $28,95 \pm 0,01 b$ & ND & 23,40 \\
\hline Cinzas (g.100g $\left.\mathrm{g}^{-1}\right) * * *$ & $1,15 \pm 0,04 \mathrm{a}$ & ND & $1,12 \pm 0,01 \mathrm{a}$ & ND & 1,30 \\
\hline Proteínas (g.100g-1 $\mathrm{g}^{-1 * *}$ & $7,98 \pm 0,04 a$ & 5,59 & $8,68 \pm 0,01 \mathrm{a}$ & 6,09 & 6,20 \\
\hline Lipídios $\left(\mathrm{g} .100 \mathrm{~g}^{-1}\right) * * *$ & $16,16 \pm 0,06 \mathrm{a}$ & 10,73 & $16,85 \pm 0,07 \mathrm{a}$ & 11,19 & 7,50 \\
\hline Carboidratos $\left(\mathrm{g} .100 \mathrm{~g}^{-1}\right) * * *$ & $44,99 \pm 0,10 \mathrm{a}$ & 7,97 & $44,40 \pm 0,11 \mathrm{a}$ & 7,87 & 60,60 \\
\hline Calorias $\left(\mathrm{kcal}^{\left.100 \mathrm{~g}^{-1}\right) * * *}\right.$ & $357,31 \pm 0,89 a$ & 8,60 & $341,50 \pm 0,59 b$ & 8,22 & 339,00 \\
\hline Fibra alimentar $\left(\mathrm{g} .100 \mathrm{~g}^{-1}\right) * * * *$ & 0,66 & 2,38 & 9,39 & 33,91 & 0,20 \\
\hline
\end{tabular}

Maiores teores de umidade foram constatados em F1 $(\mathrm{p}<0,05)$. É possível verificar, também, que as amostras (F1 e F4) mostraram valores de umidade superiores ao produto referência (IBGE, 1999). Não houve diferença entre o conteúdo de cinzas, proteínas, lipídios e carboidratos de ambas as amostras. Contudo, o teor de calorias do bolo de chá verde padrão foi mais elevado que F4 $(\mathrm{p}<0,05)$, porém maior que o produto referência (IBGE, 1999).

Destaca-se como principal resultado desse trabalho o elevado teor de fibras verificado na formulação F4 (9,39), expressando um aumento significativo de $1.322,73 \%$ em relação a F1.

\section{DISCUSSÃO}

\section{Análise sensorial}

A adição de inulina aos bolos de chá verde não promoveu modificações nos atributos de aparência, aroma, cor e textura (Tabela 2), corroborando com Aplevicz e Dias (2010) que desenvolveram biscoitos tipo "cookies" suplementados com 10, 20 e 30\% de inulina, avaliados por indivíduos adultos.

Apesar de não ter sido observada diferença estatística significativa $(p>0,05)$ na 
aparência e textura das formulações, durante o preparo das formulações foi possível verificar que quanto maior o teor de inulina adicionado, menor foi a consistência dos bolos. Esse fato pode ser explicado, pois segundo Morris e Morris (2012), a inulina interfere na elasticidade e resistência à deformação das massas interferindo na rede de glúten, resultando num produto com menor volume final.

Aplevlicz e Dias (2010) verificaram de forma similar ao presente trabalho, maior aceitação para os "cookies" padrão, nos quesitos de sabor, aceitação global e intenção de compra, quando comparados aos produtos adicionados de inulina. Segundo Grzybowski (2008) a inulina tem um poder de dulçor de $10 \%$ em relação à sacarose, o que pode explicar a redução gradual na aceitabilidade das formulações, conforme o maior teor de inulina adicionado. Assim, apesar de ter sido observado à viabilidade comercial desses produtos adicionados de inulina, são necessários mais estudos relacionados à introdução de novos ingredientes melhoradores, visando à correção das características tecnológicas alteradas.

Destaca-se que a aceitação global dos produtos F1, F2, F3 e F4 apresentou uma pontuação dentro do preconizado pelo Fundo Nacional de Desenvolvimento da Educação (FNDE) (BRASIL, 2009), (4 a 5 pontos na escala hedônica facial de 5 pontos), desta forma este produto poderia ser inserido na merenda escolar devido à elevada aceitação pelas crianças (acima de 4 pontos).

As altas notas obtidas pelos provadores (Figura 1) demonstram que a adição de inulina em bolos foi bem aceita pelo público infantil. Estes dados estão de acordo com estudos de Mota et al. (2011) que avaliaram a adição de inulina $(6,12,18$ e 24\%) em bolos light, diet $\mathrm{e}$ com alto teor de fibras, entre provadores adultos, sendo que as notas dos produtos contendo inulina variaram de 5,95 a 7,7 em uma escala hedônica de 9 pontos.

Conforme explicam Teixeira et al. (1987), um IA acima de $70 \%$ classifica os produtos com boa aceitação sensorial, dessa forma todas as formulações podem ser consideradas como bem aceitas pelas crianças. Estudos de Frutos et al. (2008) demonstraram que a adição de 3 e $6 \%$ de inulina em pães não afetaram a aceitabilidade em grande extensão entre provadores adultos. Porém, as avaliações hedônicas tendem a decrescer com a adição de inulina (DEVEREUX et al., 2003), como observou-se no presente estudo.

Segundo Alamanou et al. (2006), atributos como o aroma e sabor são as características mais importantes que influenciam as propriedades sensoriais de produtos alimentícios adicionados de 
ingredientes diferenciados. Em razão disso, a amostra F4 (9\% de inulina) foi selecionada para fins de comparação, juntamente com a padrão $(\mathrm{F} 1)$, por ser aquela com o maior teor de inulina e com aceitação semelhante à padrão (atributo sabor).

\section{Composição físico-química}

Quanto à avaliação físico-química, os maiores valores de umidade encontrados em F1 e F4, quando relacionados ao produto referência se devem, provavelmente, devido à adição de iogurte natural em ambas as formulações, o qual possui um elevado teor de água (90\%) (IBGE, 1999; TACO, 2011).

No presente estudo os teores de cinzas das amostras permaneceram similares, porém, em estudos de Moscatto et al. (2004), avaliando a adição de $6 \%$ de inulina em bolo de chocolate, observaram-se maiores teores de cinzas no produto com inulina $(1,93 \%)$ do que no padrão $(1,42 \%)$, o que se deve, possivelmente, aos diferentes ingredientes utilizados nas formulações. Já, o fato de não ter sido constada diferença entre os teores de proteínas e lipídios nos bolos, pode ser explicado uma vez que tanto a inulina quanto o açúcar não contém esses nutrientes em sua composição (TACO, 2011). Entretanto, menores teores de lipídios em bolos contendo inulina $(6 \%)$ foram relatados em trabalhos de
Moscatto et al. (2004), fato que pode ter ocorrido, também devido a substituição da farinha de trigo por farinha de yacon (40\%).

$\mathrm{Na}$ presente pesquisa, o maior conteúdo calórico observado em F1 ocorreu porque F4 foi formulada com teor reduzido de açúcar em relação à F1. Além disso, o açúcar foi substituído pela inulina, a qual contém menor conteúdo de calorias $(1,5 \mathrm{kcal} / \mathrm{g})$ em relação ao açúcar (4 kcal/ g) (ATWATER; WOODS, 1896; BENEO ${ }^{\circledR}$ HP, 2015).

Durante a infância e adolescência são comuns hábitos alimentares como o consumo excessivo de refrigerantes, açúcares e lanches do tipo fast food. Este fato se torna preocupante visto que pode levar ao excesso de peso e a maior probabilidade de doenças crônicas não transmissíveis (DCNT) como diabetes, hipertensão arterial e dislipidemias na vida adulta (VON ATZINGEN et al., 2010). Desta forma, percebe-se a importância de oferecer às crianças produtos com teores reduzidos de calorias e açúcares, assim como o produto desenvolvido neste estudo.

O elevado teor de fibras constatado em F5 (Tabela 2) se explica, principalmente, devido ao alto teor de fibra alimentar presente na inulina $(97,00 \%)$. Estes resultados tornam o produto uma excelente opção alimentar para crianças em idade escolar, uma vez que, em 
geral, este grupo se destaca pela baixa ingestão de fibras (RINALDI et al., 2008).

Segundo a Legislação Brasileira (BRASIL, 1998), um produto é considerado fonte de fibras quando apresenta no mínimo 3\% e com alto teor no mínimo 6\% de fibras. Desta forma, a formulação $\mathrm{F} 4$ pode ser considerada como um alimento com alto teor de fibras.

\section{CONCLUSÕES}

O desenvolvimento dos produtos permitiu comprovar que um nível de adição de até 9\% de inulina em bolo de chá verde (redução de $75 \%$ do açúcar), foi bem aceito pelos provadores, obtendo-se aceitação sensorial semelhante ao produto padrão.

A adição de 9\% de inulina em bolo de chá verde reduziu a umidade e o teor calórico, elevando expressivamente o aporte de fibras, melhorando assim o perfil nutricional do produto. Assim sendo, a inulina pode ser considerada um potencial ingrediente com propriedades funcionais, para adição em bolos e produtos similares, podendo ser oferecidos aos consumidores infantis com altas expectativas de aceitação no mercado.

\section{REFERÊNCIAS}

ALAMANOU, S.; et al. Influence of protein isolate from lupin seed (Lupinusalbus. ssp. Graecus) on processing and quality characteristics of frankfurters. Meat Sci., v.42, n.1, p.79-93, 1996.

AOAC. International. Official Methods of Analysis of AOAC International. 18 ed. 4 rev. Gaithersburg: MD, 2011. 1505p.

APLEVLICZ, K.S.; DIAS, L.F. Suplementação de inulina em biscoitos tipo cookie. Food Ingred. Bras., v.1, n.11, p.34-38, 2010.

ATWATER, W.O.; WOODS, C.D. The chemical composition of American food materials. Farmers' Bulletin, n.28. U.S. Department of Agriculture. Washington, 1896.

BENEO $^{\circledR}$ HP. Product Sheet Beneo ${ }^{\circledR}$ HP, Orafti, DOC.A4-05*01/02-B. Disponível em: http://www.orafti.com. Acesso em: 07/11/15.

BLIGH, E.G.; DYER, W.J. A rapid method of total lipid extraction and purification. Can. J. Biochem. Physiol., v.37, p.911-917. 1959.

BRASIL - Ministério da Saúde. Secretaria de Atenção à Saúde. Departamento de Atenção Básica. Política Nacional de Alimentação e Nutrição. Brasília, DF, 2003. Disponível em: http://nutricao.saude.gov.br/docs/geral/pnan.pdf Acesso em: 12/10/2013.

BRASIL. Ministério da Educação. Fundo Nacional de Desenvolvimento da Educação.

Resolução/FNDE/CD/n.38, de 16 de Julho de 2009. PNAE. Brasília, DF, 2009.

BRASIL. Ministério da Saúde. Secretaria de Vigilância Sanitária (SVS/MS). Portaria n. 27, de 13 de janeiro de 1998. Regulamento técnico referente à informação nutricional complementar. Diário Oficial da República Federativa do Brasil, Brasília, DF, 1998.

CECANE - Centro colaborador em alimentação e nutrição escolar. Manual para aplicação dos testes de aceitabilidade no Programa Nacional de Alimentação Escolar - PNAE. UNIFESP, 2010. 55p. 
DEVEREUX, H. M.; et al. Consumer acceptability of low fat foods containing inulin and oligofructose. J. Food Sci., v.68, n.5, p.1850-1854, 2003.

DIETARY REFERENCE INTAKES (DRI).

Dietary reference intakes for: energy, carbohydrate, fiber, fat, fatty acids, cholesterol, protein and amino acids (macronutrients).

Washington, DC: National Academic Press, 2005. 1331p.

FRUTOS, M. J. et al. Effect of artichoke (Cynara scolymus L.) fiber on textural and sensory qualities of wheat bread. Food Sci. Technol. Int., v.14, n.5, p.49-55, 2008.

GASTALDON, L.T. et al. Análise sensorial de empadas integrais em crianças na fase escolar. Alim. Nut., v.18, n.3, p.303-307, 2007.

GRZYBOWSKI, A. Hidrólise parcial cítrica ou fosfórica de inulina para obtenção de fruto-oligossacarídeos. 2008. 78f. Tese (Mestrado em Ciências Farmacêuticas). Curitiba (PR): Setor Ciências da Saúde, Universidade Federal do Paraná; 2008.

IBGE - Instituto Brasileiro de Geografia e Estatística. Secretaria de Estado de Planejamento e Avaliação. Tabelas de Composição de Alimentos. Rio de Janeiro: Ministério da Fazenda, 1999. 137p.

KIMMEL, S.A.A.; SIGMAN-GRANT, M.; GUINARD, J. Sensory testing with young children. Food Technol., v.48, n.3, p.92-99, 1994.

MINIM, V.P.R. Análise Sensorial: estudo com consumidores. 2. ed. Viçosa, MG: UFV, 2010. 308p.

MONTEIRO, C.L.B. Técnicas de avaliação sensorial. 2.ed. Curitiba: CEPPA-UFPR, 1984. $101 \mathrm{p}$.
MORRIS, C.; MORRIS, G.A. The effect of inulin and fructo-oligosaccharide supplementation on the textural, rheological and sensory properties of bread and their role in weight management: A review. Food Chem., v.133, n.2, p.237-248, 2012.

MOSCATTO, J.A.; PRUDÊNCIO-FERREIRA, S.H.; HAULY, M.C. Farinha de yacon e inulina como ingredientes na formulação de bolo de chocolate. Ciênc. Tecnol. Alim., v.24, n.4, p.634-640, 2004.

MOTA, M.C. et al. Bolo light, diet e com alto teor de fibras: elaboração do produto utilizando polidextrose e inulina. Rer. Inst. Adolfo Lutz., v.70, n.3, p.268-75, 2011.

MUCCILLO-BAISCH, A.L.; VILANOVA, L.B.; PERAZA, G. Efeitos do extrato aquoso da Camellia sinensis, associado ao exercício físico, no modelo experimental de hipercolesterolemia. Vittalle, v.21, n.2, p.5368, 2009.

RINALDI, A.E.M.; et al. Contribuições das práticas alimentares e inatividade física para o excesso de peso infantil. Rev. Paul. Pediatr., v.26, n.3, p.271-277, 2008.

ROBERFROID, M.B. Introducing inulin-type fructans. British J. Nutr., v.93, n.1, p.S13-S25, 2005.

SAAD, S.M.I. Probióticos e prebióticos: o estado da arte. Rev. Bras. Ciênc. Farm., v.42, n.1, p.53-69, 2006.

SANTOS, E.F. et al. Alimentos funcionais. Rev. Pesq. Bibliogr. UNIFEV, v.1, n.1, p.1319, 2006.

TACO - Tabela Brasileira de Composição dos Alimentos. 4 ed. Revisada e ampliada. Campinas, SP: NEPA, 2011. 161p. 
TEIXEIRA, A.E.; MEINERT E.; BARBETTA, $P . A$. Análise sensorial dos alimentos,

Florianópolis: UFSC, 1987. 182p.

VON ATZINGEN, M.C.B.C.; PINTO E

SILVA, M.E.M. Sensory characteristics of food as a determinant of food choices. Nutrire, v.35, n.3, p.183-196, 2010.

ZHANG, Q. et al. Green tea extract and (-)epigallocatechin-3-gallate inhibit hypoxia- and serum-induced HIF-1alpha protein accumulation and VEGF expression in human cervical carcinoma and hepatoma cells. Mol.

Cancer Ther., v.5, n.5, p.1227-1238, 2006. 